ARTICLE

Received 24 Jul 2013 | Accepted 23 Jan 2014 | Published 25 Feb 2014

DOI: $10.1038 /$ ncomms 4304

OPEN

\title{
Potential climate engineering effectiveness and side effects during a high carbon dioxide-emission scenario
}

David P. Keller ${ }^{1}$, Ellias Y. Feng ${ }^{1} \&$ Andreas Oschlies ${ }^{1}$

The realization that mitigation efforts to reduce carbon dioxide emissions have, until now, been relatively ineffective has led to an increasing interest in climate engineering as a possible means of preventing the potentially catastrophic consequences of climate change. While many studies have addressed the potential effectiveness of individual methods there have been few attempts to compare them. Here we use an Earth system model to compare the effectiveness and side effects of afforestation, artificial ocean upwelling, ocean iron fertilization, ocean alkalinization and solar radiation management during a high carbon dioxide-emission scenario. We find that even when applied continuously and at scales as large as currently deemed possible, all methods are, individually, either relatively ineffective with limited $(<8 \%)$ warming reductions, or they have potentially severe side effects and cannot be stopped without causing rapid climate change. Our simulations suggest that the potential for these types of climate engineering to make up for failed mitigation may be very limited.

\footnotetext{
${ }^{1}$ Marine Biogeochemical Modelling, GEOMAR Helmholtz-Zentrum für Ozeanforschung Kiel, Düsternbrooker Weg 20, 24105 Kiel, Germany. Correspondence and requests for materials should be addressed to D.P.K. (email: dkeller@geomar.de).
} 
T he realization that despite all mitigation efforts to reduce $\mathrm{CO}_{2}$ emissions atmospheric $\mathrm{CO}_{2}$ concentrations are still rapidly increasing and closely follow the IPCC's high emission scenario ${ }^{1}$ has led to an increasing interest in climate engineering as a potential means of preventing the potentially unacceptable consequences of global warming ${ }^{2,3}$. Evaluating the potential effectiveness and risks of different climate engineering methods prior to any large-scale field experiments is an important first step in informing scientists and society if, and how, further research or physical experimentation should be done ${ }^{4}$. Besides providing information regarding potential opportunities and risks, theoretical research has also proven to be a useful way to learn about the climate system. While there is a growing body of literature on individual methods, comparisons among different studies are difficult to make when the studies have been conducted with different models and climate change scenarios ${ }^{3}$. A previous comparison of the radiative forcing potential of different climate engineering methods ${ }^{5}$ addressed the question of how efficient the methods are at preventing global warming. However, the analytical methodology that was used did not allow for the quantification of side effects and the possible feedbacks in the climate system that may cause a method to be more or less effective than predicted. Earth system models can be used to better evaluate the effectiveness, side effects and climate feedbacks of different climate engineering methods in a comprehensive way, but have not yet been used to compare different climate engineering methods.

The objective of this paper is to compare and assess the potential effectiveness, in terms of intended climate remediation, as well as the unintended physical and biogeochemical side effects of several climate engineering methods (Table 1) during transient Earth system simulations with a high $\mathrm{CO}_{2}$ emissions representative concentration pathway (RCP 8.5) scenario $^{6}$ (Fig. 1). We employ the University of Victoria Earth system model (UVic) ${ }^{7,8}$, a model of intermediate complexity (EMIC), and investigate various climate engineering methods of different character in terms of deployment medium, spatial and temporal scales, as well as ethical, legal and cultural aspects. These methods are large-scale afforestation (AF), ocean iron fertilization (OIF), artificial ocean upwelling (OU), ocean alkalinization (OA) and solar radiation management (SRM). For simplicity, our approach for many of the methods is idealized to simulate the effects that deploying a method would have, without introducing unnecessary complexity (see Methods). Moreover, we also evaluate the methods in a manner that essentially investigates near-maximum potential effects (that is, large to global-scale deployments with an intensity as large as currently deemed feasible-see Methods). The economic, legal, political and technological feasibility of the methods are not considered here, nor are ethical aspects. Instead we focus solely on the potential atmospheric $\mathrm{CO}_{2}$ reductions, climate impacts and the physical and biogeochemical side effects of each method. We find that even when applied continuously at scales as large as currently deemed possible, all methods are, individually, either relatively ineffective with limited warming reductions, or they have potentially severe side effects and cannot be stopped without causing rapid climate change. Our simulations suggest that the potential for these types of climate engineering to make up for failed mitigation may be very limited.

\section{Results}

Model trends during the RCP 8.5 climate change scenario. The UVic model has recently been evaluated in several model intercomparison exercises $^{9-11}$ and generally has a similar response to $\mathrm{CO}_{2}$ emission forcing as other models. Here we will briefly mention how the results of our RCP 8.5 scenario control run (Supplementary Figs 1-3) compared with other models. We will also point out the trends that differ from other models since these (possible) biases need to be taken into consideration when evaluating the model's response to climate engineering. For surface air temperature the model simulates a global mean warming of $3.1^{\circ} \mathrm{C}$ by the year 2100 relative to a $1986-2005$ reference period (see also Fig. 2c for warming relative to the pre-industrial period), which is within the ranges of an EMIC intercomparison $\left(1.6-4.1^{\circ} \mathrm{C}\right)^{10}$ and the CMIP5 models $\left(2.5-5.0^{\circ} \mathrm{C}\right)^{12}$. Atlantic meridional overturning circulation decreases by $38 \%$ in our simulation, which is near the mean $(40 \%)$ and within the range (36-44\%) of 26 other models (mostly

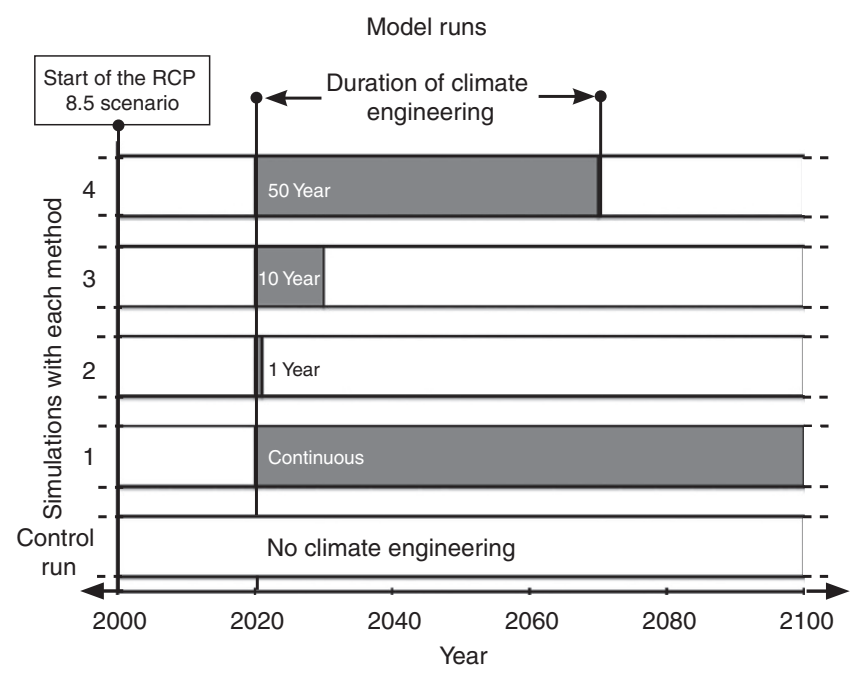

Figure 1 | Experimental design. The simulations performed for each climate engineering method. The control run is also depicted.

Table 1 | Climate engineering methods evaluated.

\begin{tabular}{|c|c|c|}
\hline Method & Description & Objective \\
\hline Afforestation (AF) & $\begin{array}{l}\text { Irrigation of North African and Australian } \\
\text { deserts to allow vegetation to grow }\end{array}$ & Increase terrestrial $\mathrm{CO}_{2}$ uptake and storage \\
\hline Artificial ocean upwelling (OU) & $\begin{array}{l}\text { Use long pipes to pump deep, cold nutrient } \\
\text { rich water to the ocean's surface }\end{array}$ & $\begin{array}{l}\text { Cool ocean surface waters } \\
\text { Fertilize the surface ocean to increase the biological } \\
\text { pump and ocean carbon storage }\end{array}$ \\
\hline Ocean alkalinization (OA) & $\begin{array}{l}\text { Increase surface-ocean alkalinity by adding } \\
\text { lime }\left(\mathrm{Ca}(\mathrm{OH})_{2}\right)\end{array}$ & $\begin{array}{l}\text { Chemically increase the oceanic uptake of } \\
\text { atmospheric } \mathrm{CO}_{2}\end{array}$ \\
\hline Ocean iron fertilization (OIF) & $\begin{array}{l}\text { Eliminate phytoplankton iron limitation in the } \\
\text { Southern Ocean }\end{array}$ & $\begin{array}{l}\text { Increase ocean productivity to enhance the biological } \\
\text { pump and ocean carbon storage }\end{array}$ \\
\hline Solar radiation management (SRM) & Reduce the amount of incoming solar radiation & Prevent warming by reducing solar radiation absorption \\
\hline
\end{tabular}


CMIP5 models $)^{11}$. For ocean biogeochemistry a CMIP5 model intercomparison study has not yet been published so instead we have made comparisons to the Community Earth System Model (CESM1 (BGC)) RCP 8.5 scenario results ${ }^{13}$. By the year 2100 export production has decreased by $11 \%$ in our simulation and $13 \%$ in the CESM1 simulation. Net primary production decreases by $5.8 \%$ in our simulation and $5.7 \%$ in the CESM1 simulation. Mean ocean oxygen decreases by $7 \mu \mathrm{M}$ in our simulation (see also Fig. $2 \mathrm{~g}$ for the global total change in oxygen) and $10 \mu \mathrm{M}$ in the CESM1 simulation. However, for the volume of the oxygen minimum zones (OMZ), our results are in contrast to CESM1, since our simulation shows a decrease in the size of the OMZs (Supplementary Fig. 4) and theirs show an increase of $24 \%$. Since most Earth system models have problems simulating oxygen distributions and the volume of OMZs it is difficult to determine which trend is correct ${ }^{13-15}$, although observations suggest that OMZs have been expanding in recent decades ${ }^{16}$. Evaluating terrestrial carbon uptake or loss is difficult since there are large differences (that is, uncertainty) in total carbon uptake between the CMIP5 models (ranging from -0.97 to $2.27 \mathrm{Pg} \mathrm{Cy}^{-1}$ during 2006-2100), with some models predicting that the terrestrial biosphere will become a net source of carbon and other predicting that it will become a larger $\operatorname{sink}^{17}$. In our simulation the terrestrial biosphere becomes a larger sink with a terrestrial carbon pool in the year 2100 (Table 2) that is $15 \mathrm{PgC}$ larger than the highest value reported for the CMIP5 models ${ }^{17}$. For soil moisture our model indicates that globally soil moisture will decrease in June, July and August and increase in December, January and February (DJF). The first result is largely consistent with CMIP5 model results $^{18}$. However, the majority of CMIP5 models indicate that while a large proportion of the globe will have higher soil moisture in DJF an even larger proportion will have drier conditions $^{18}$, which is inconsistent with our results. For precipitation our model does not show a global increase of $1-3 \% \mathrm{~K}^{-1}$ as warming occurs, which is inconsistent with most models $^{19-21}$. Instead global precipitation in the model decreases
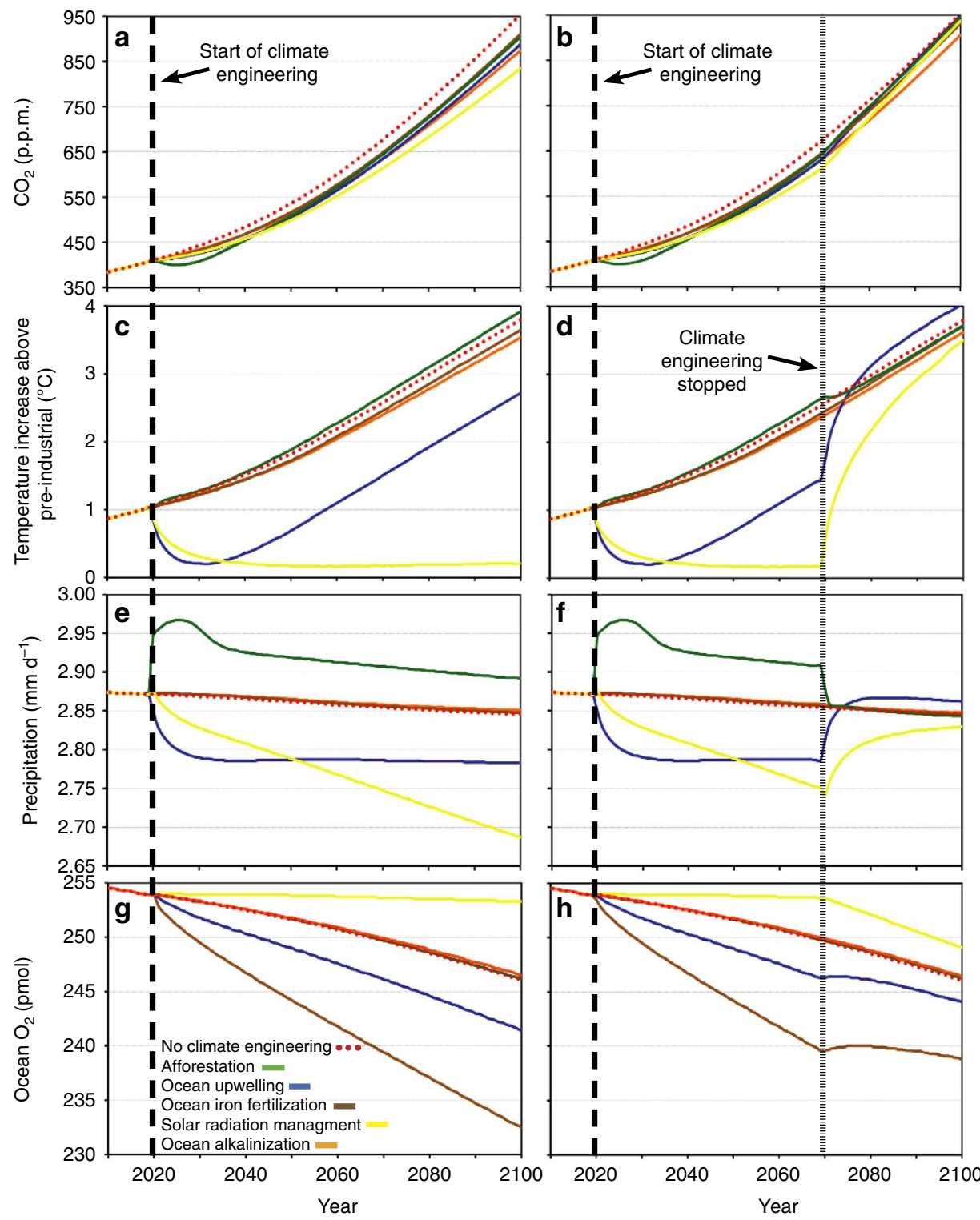

Figure 2 | Comparison of climate engineering method effects on key global properties. Simulated changes in globally averaged annual atmospheric $\mathrm{CO}_{2}$ and surface air temperature (relative to a pre-industrial temperature of $13.05^{\circ} \mathrm{C}$ ) and the total amount of annual global precipitation and ocean oxygen for model runs where climate engineering was continuously deployed $(\mathbf{a}, \mathbf{c}, \mathbf{e}$ and $\mathbf{g})$ and runs where it was discontinued after 50 years $(\mathbf{b}, \mathbf{d}, \mathbf{f}$ and $\mathbf{h})$.

The control run, with no climate engineering, is also shown. 
Table 2 | Climate engineering induced changes in global temperature and carbon inventories.

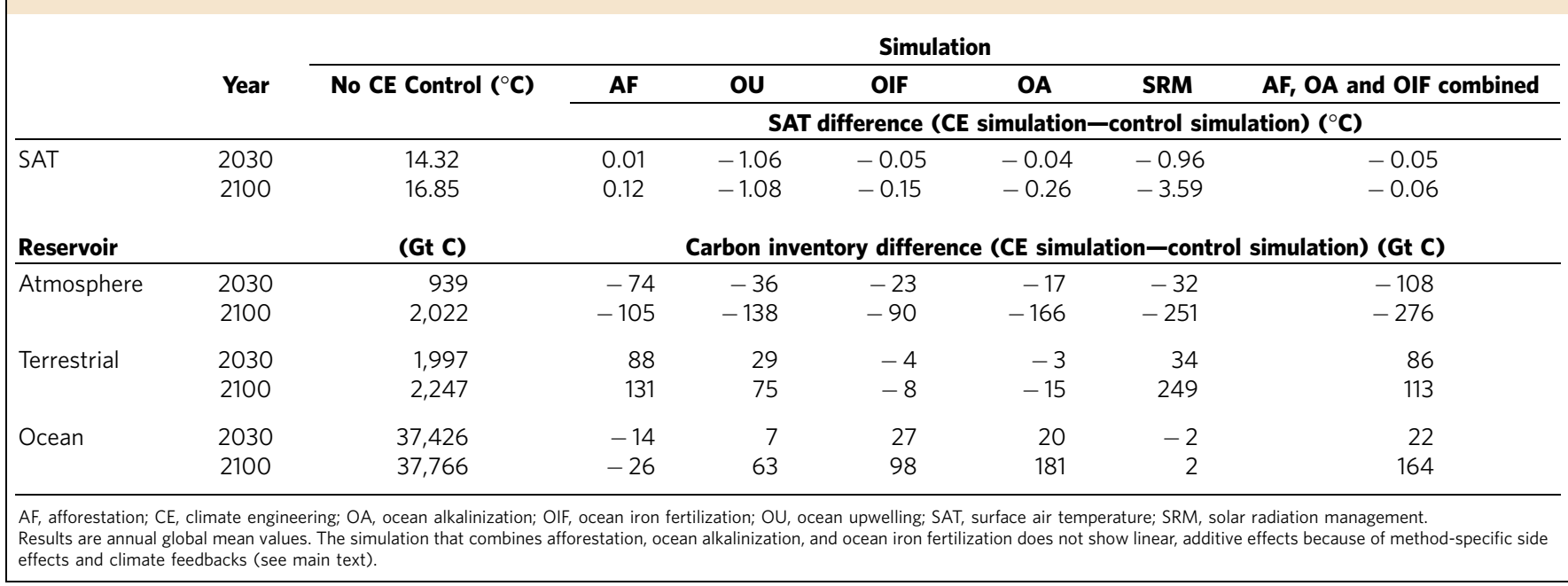

Table 3 | Climate engineering induced changes in key Earth system properties.

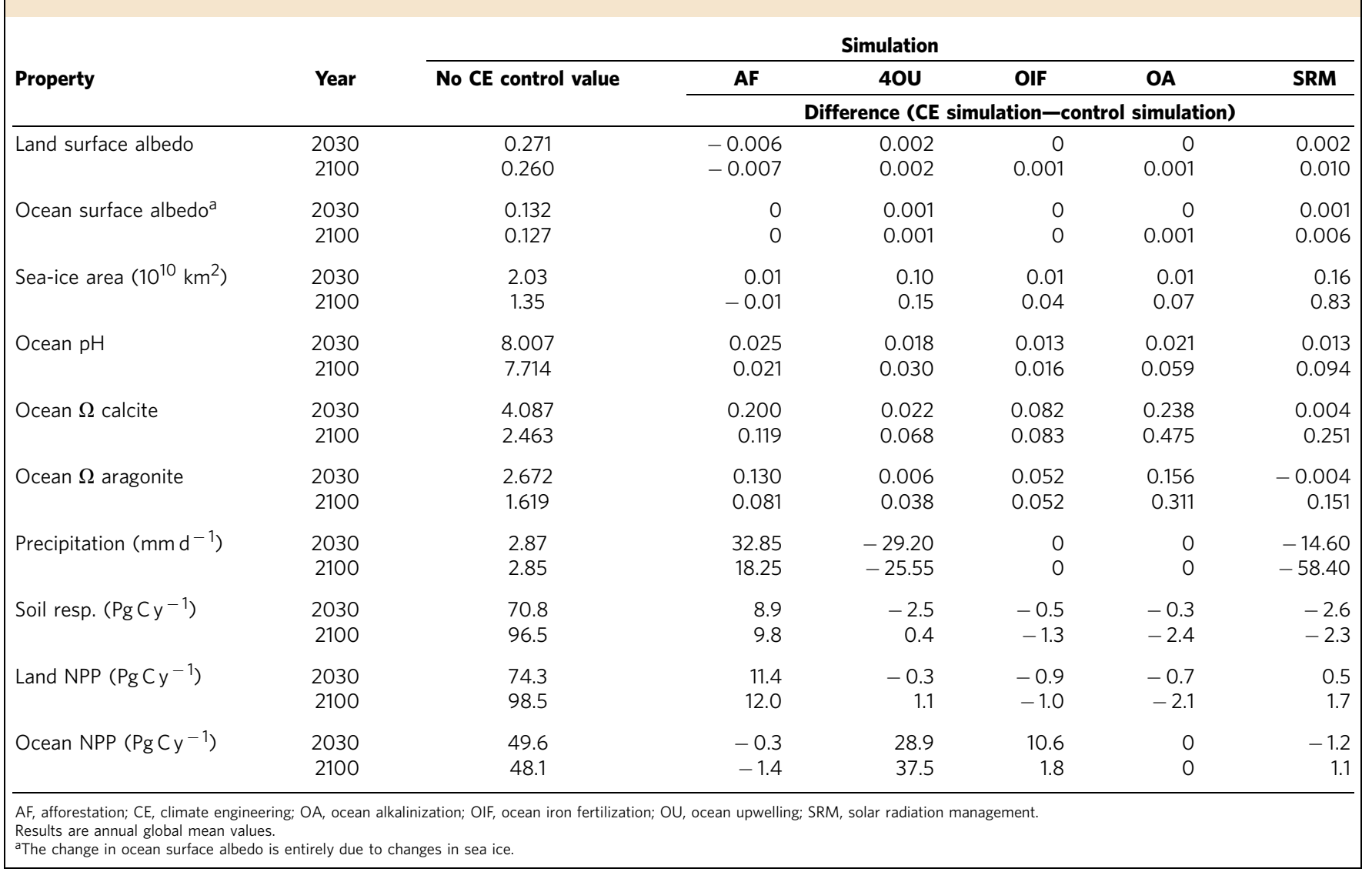

by $0.3 \% \mathrm{~K}^{-1}$ (see also Fig. 2e and Table 3 for mean annual changes). This inconsistency occurs despite an increase in atmospheric water vapour of $7.4 \% \mathrm{~K}^{-1}$, which is consistent with other models, observations, and in line with the ClausiusClaperyron equation ${ }^{19-21}$. The decrease in global precipitation is entirely due to a decrease in terrestrial precipitation of $3.41 \% \mathrm{~K}^{-1}$ since precipitation and evaporation over the ocean increase by $\sim 1.26 \% \mathrm{~K}^{-1}$, which is in good agreement with other models
(Supplementary Fig. 5). The decrease in terrestrial precipitation is related to the simulated sensitivity of evapotranspiration to increasing $\mathrm{CO}_{2}$ (that is, the physiological response of plant stomata to $\mathrm{CO}_{2}$ fertilization and its effect on water vapour loss), which results in a reduction in terrestrial evaporation of $8 \% \mathrm{~K}^{-1}$. While this strong decrease in evapotranspiration is inconsistent with the general trend of other models (despite significant differences and uncertainty among them ${ }^{22}$ ), recent research ${ }^{23}$ has 
suggested that existing theory and the 13 most commonly used terrestrial biosphere models underestimate forest water-use efficiency when $\mathrm{CO}_{2}$ increases.

Climate engineering method effects on temperature and $\mathrm{CO}_{2}$. When climate engineering is deployed continuously from the year 2020 onward, atmospheric $\mathrm{CO}_{2}$ is reduced in all of the simulations (Fig. 2a, Table 2). However, these reductions are small compared with expected business-as-usual anthropogenic emissions, and atmospheric $\mathrm{CO}_{2}$ continues to increase rapidly and still reaches more than twice the current level by the end of the century in all simulations. Those methods that have been proposed to reduce atmospheric $\mathrm{CO}_{2}$ as a means of preventing warming, that is, carbon dioxide reduction (CDR) methods (Table 1), are thus, as expected from other studies ${ }^{3,5,24-27}$, unable to prevent a $2.7-3.9^{\circ} \mathrm{C}$ mean temperature increase (temperature increases by $3.8^{\circ} \mathrm{C}$ with no climate engineering) in our model simulations under the RCP 8.5 emission scenario by the year 2100 (Table 2, Figs $2 c$ and $3 a, c, e, g)$. Indeed, the albedo change caused by simulated AF (Table 3, Supplementary Fig. 6b) actually results in more warming (see text below for details) than if no climate engineering was implemented. SRM is the only method in our
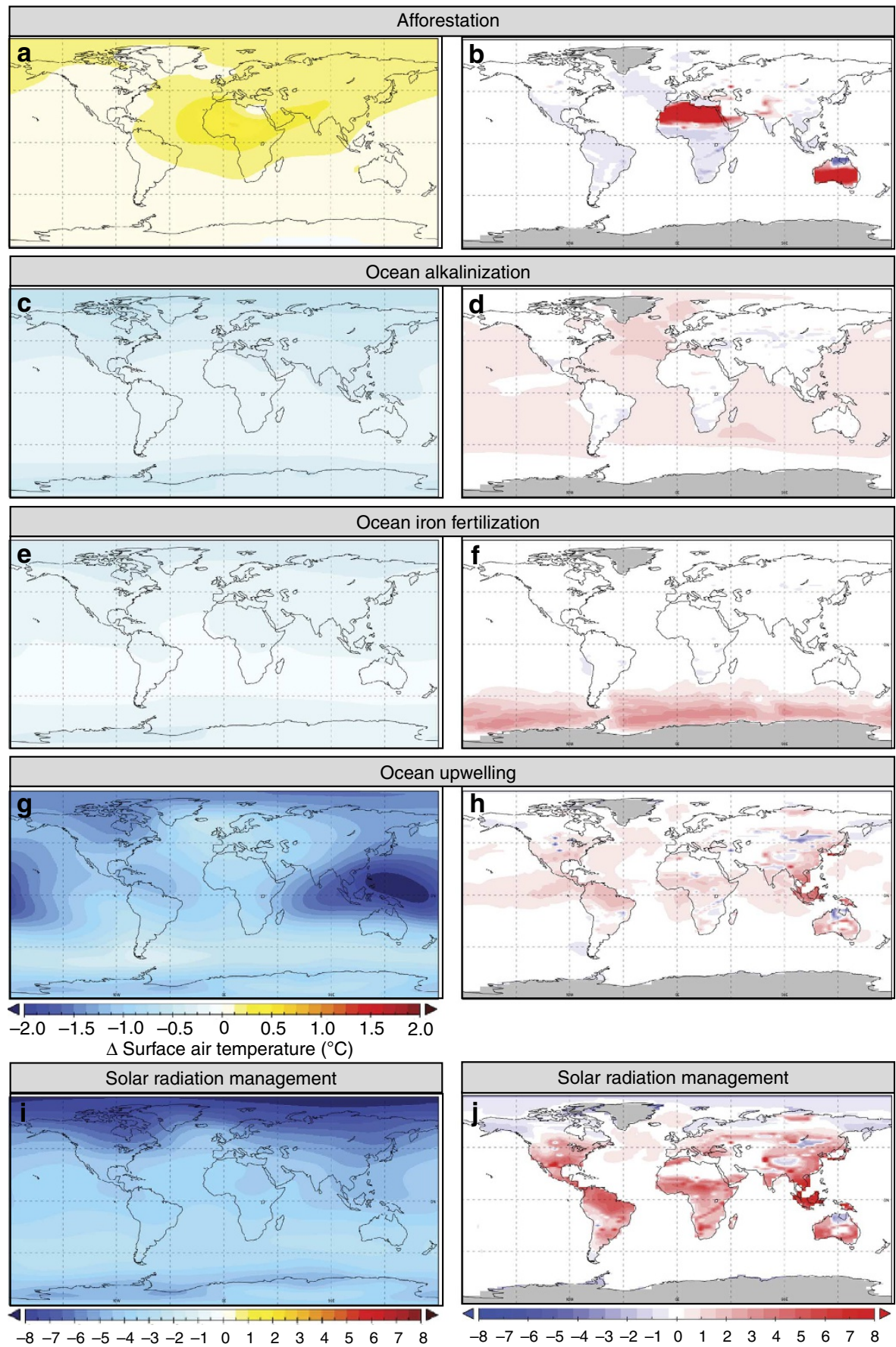

$\Delta$ Oceanic and terrestrial $\mathrm{C}\left(\mathrm{Kg} \mathrm{m}^{-2}\right)$

Figure 3 | Climate engineering method effects on temperature and carbon storage. The simulated year 2100 mean annual differences between the climate engineering runs and the control run (climate engineering run minus the control run) for surface air temperature (a,c,e,g and $\mathbf{i}$ ) and terrestrial and oceanic carbon inventories $(\mathbf{b}, \mathbf{d}, \mathbf{f}, \mathbf{h}$ and $\mathbf{j}$ ). Note the difference in the surface air temperature scale for solar radiation management. 
simulations that is potentially able to restore the temperature to a near pre-industrial value within the twenty first century (Table 2, Figs $2 \mathrm{c}$ and $3 \mathrm{i}$ ) and to prevent many warming-related Earth system changes from occurring (Supplementary Figs 6i,j, $7 \mathrm{i}, \mathrm{j}, 8 \mathrm{j}$ and $9 \mathrm{e})$. However, as already known from other studies employing different scenarios ${ }^{28,29}$, a persistent reduction of warming requires that SRM is applied continuously.

Discontinuation of climate engineering. If SRM is discontinued at any time then extremely rapid warming occurs (up to $0.36^{\circ} \mathrm{Cy}^{-1}$ ), along with an increased rate of atmospheric $\mathrm{CO}_{2}$ accumulation (Fig. 2b,d; Supplementary Fig. 10). For temperature, this termination effect is well known and has been consistently reproduced in SRM studies ${ }^{28-32}$. However, there is much less certainty concerning the response of the carbon cycle to SRM discontinuation ${ }^{30}$. Here we show that there is a substantial termination effect on the carbon cycle since the reduction in atmospheric $\mathrm{CO}_{2}$, which for the simulated SRM deployment is even larger than that of the CDR methods (Table 2, Fig. 2a), quickly reverses with atmospheric $\mathrm{CO}_{2}$ levels reaching those of the control run within a few decades (Fig. 2b). For OU, rapid warming (up to $0.33^{\circ} \mathrm{Cy}^{-1}$ ) also occurs when it is discontinued, with surface air temperature ultimately becoming $0.24^{\circ} \mathrm{C}$ higher, due to the method's impacts on the planetary energy budget (see below and ref. 27, than if the method had not been deployed at all. Atmospheric $\mathrm{CO}_{2}$ concentrations also rise again with the discontinuation of $\mathrm{OU}$ until they are at essentially the same level as if no climate engineering had occurred. If the other methods are discontinued less dramatic changes occur. When OIF and $\mathrm{OA}$ are discontinued then the ocean stops taking up $\mathrm{CO}_{2}$ at a higher rate (Fig. 2b; Supplementary Fig. 10). However, essentially all of the $\mathrm{CO}_{2}$ that was taken up (Fig. 3d,f) remains in the ocean throughout the duration of the simulation and atmospheric $\mathrm{CO}_{2}$ concentrations are 21 (OIF) and 48 (OA) p.p.m. lower in the year 2100 than if the methods had not been deployed at all. Because of this, surface air temperatures in the OIF and OA simulations always remain slightly lower, by 0.09 and $0.18^{\circ} \mathrm{C}$ by the year 2100 , respectively, than in the control run (Fig. 2d; Supplementary Fig. 10). For OIF, this result is consistent with an earlier study ${ }^{26}$.

When $\mathrm{AF}$ is discontinued by stopping irrigation, the afforested desert regions eventually return to a desert state and the carbon that was stored in the plant biomass and soil (Fig. 3b) is slowly returned to the atmosphere through decay and respiration. As the vegetation related albedo change ends the surface air temperature drops from slight slightly higher $\left(0.1^{\circ} \mathrm{C}\right)$ to slightly lower $\left(0.08^{\circ} \mathrm{C}\right.$ ) than the control run (Table 3, Supplementary Fig. 6; see also text below), which is an effect that has been seen in other studies of deforestation ${ }^{33}$. The temperature becomes slightly lower than in the control run because atmospheric $\mathrm{CO}_{2}$ is lower since not all of the stored carbon has returned to the atmosphere by the year 2100 and because during desertification the deserts expand ( $\sim 1-3$ model grid cells; not shown) beyond their former range (for example, the desert areas in the control simulation). Since more desert area increases the land surface albedo this contributes to the slight decrease in surface air temperature. The expansion of the deserts occurs because during simulated AF the vegetation in the grid cells next to the irrigated regions receive more water due to runoff and additional precipitation (see text below) and thus the vegetation changes from grass land (C3 and C4 types), as in the control simulation, to a shrub type. When simulated irrigation stops, the vegetation is unable to revert from a shrub type to grass types in our model world that has undergone climate change and instead becomes a desert. Similar shifts in vegetation have been observed in other simulations in response to perturbations 34 .
Efficacy of the climate engineering methods. Although most of the CDR methods (Table 1) appear to gradually affect atmospheric $\mathrm{CO}_{2}$ and the surface air temperature (Fig. 2a,b), their CDR efficacy is actually quite non-linear with time (Fig. 4b-d), and there is often a backflux of carbon from non-targeted areas as they adjust to the change in atmospheric $\mathrm{CO}_{2}$ (for example, the ocean in the case of AF; backfluxes may also occur within the reservoirs). Indeed, even with SRM, whose purpose is to gradually reduce incoming solar radiation (Fig. 4a) to regulate the surface air temperature, the effectiveness-amplifying (in terms of surface air temperature reductions) CDR side effects (mainly on terrestrial productivity and soil respiration; see text below) are substantial (Fig. 4b-d; Supplementary Fig. 11). Some CDR methods like AF, OIF and OU are quite effective on short time scales (peak $\mathrm{C}$ removal occurs in the first 5 years), but less so on longer ones, a result that has been previously shown for OIF and OU ${ }^{25-27}$. In contrast, $\mathrm{CDR}$ for $\mathrm{OA}$ increases in effectiveness over time (Fig. $4 \mathrm{~b}-\mathrm{d}$ ) because the ocean-buffering capacity ${ }^{35}$ remains high, unlike in the other simulations, even as atmospheric $\mathrm{CO}_{2}$ increases, thus allowing the ocean to take up more $\mathrm{CO}_{2}$. For SRM, CDR per change in insolation is highest during the first few years, then declines, and then gradually increases in intensity again (Fig. 4b-d, Supplementary Fig. 11). The change in surface air temperature per change in insolation for SRM occurs mostly during the first decade of deployment (Fig. 2c, Supplementary Fig. 11). These results highlight the non-linear relationship between changes in temperature and $\mathrm{CO}_{2}$, illustrated in Fig. $4 \mathrm{~d}$, that occur because of other, often method-specific, feedbacks involving, among others, the hydrological cycle, vegetation and ocean chemistry (see text below).

Side effects of the climate engineering methods. All of the methods have unintended side effects. Here we mainly focus on physical and biogeochemical side effects that can be diagnosed with the current model (Tables 3 and 4), but we will also mention some other commonly discussed ones. When possible, we have tried to indicate whether a system or cycle will be perturbed by a side effect, but in most cases we are unable to make robust inferences on specific responses to a perturbation (for example, how species or small-scale regions may be affected).

The side effects of AF tend to be regional, with the large-scale regions defined here as N. Africa, Australia and the surrounding few hundred kilometres. However, although regional changes would certainly be expected, caution must be taken when interpreting the robustness of these results since the model has fixed atmospheric circulation patterns that essentially do not change (see methods) in response to AF. Regional precipitation and terrestrial productivity both increase (Table 2, Supplementary Figs $6 \mathrm{a}$ and $12 \mathrm{a}, \mathrm{c})$, which could be beneficial for some species and, presumably, humans as long as the increase in precipitation does not cause severe storms or flooding. However, these changes would have a large and perturbing impact on local ecosystems and any societies that depend on them. Productivity increases because in addition to the direct effects of having more water from irrigation, which allows plants to grow in a former desert, there is the fertilizing effect of increasing $\mathrm{CO}_{2}$ on growth ${ }^{23}$. Increasing $\mathrm{CO}_{2}$ during the simulations has a further effect on vegetation and the hydrological cycle because vegetation water-use efficiency increases with increasing atmospheric $\mathrm{CO}_{2}$ concentrations $22,23,36$. Although the increase in precipitation is regional it increases the total amount of global precipitation (Fig. 2e) because more water is added to the hydrological cycle. The higher soil moisture and precipitation, which also result in more terrestrial runoff into the ocean, thereby decrease coastal salinity (Supplementary Fig. $7 \mathrm{~b}$ ) and raise the global mean sea 

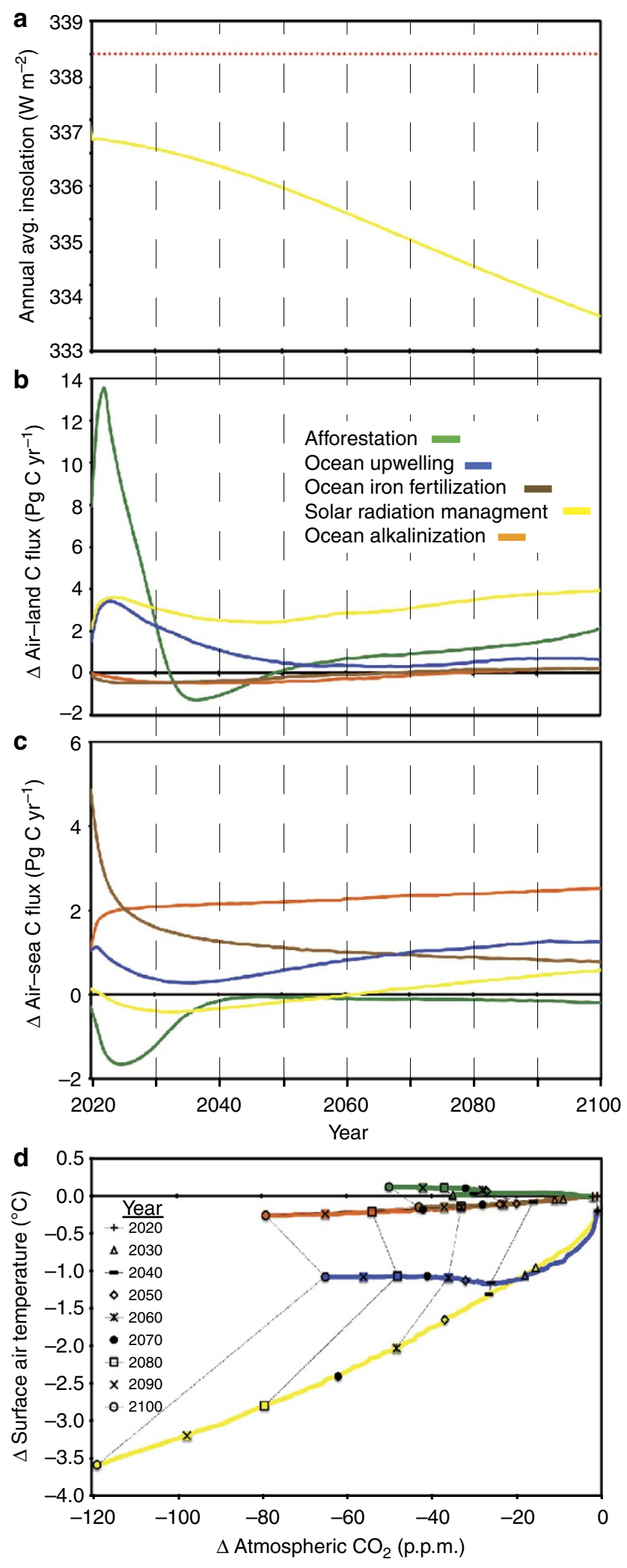

Figure 4 | Comparison of climate engineering method effectiveness.

(a) Insolation at the top of the atmosphere for the SRM (yellow line) model run and all other simulations (dotted red line). The climate engineering model run differences (relative to the no climate engineering model run) in the annually averaged fluxes of carbon from the atmosphere to the (b) land and (c) ocean. Comparison (d) of surface air temperature versus atmospheric $\mathrm{CO}_{2}$ differences (relative to the no climate engineering model run) for the climate engineering simulations. level by $\sim 13 \mathrm{~cm}$ in the year 2100 , unless the water used for irrigation is desalinated seawater. As a result of this change in salinity regional ocean circulation patterns (Supplementary Fig. 8b) and ecosystems would likely be affected as well. Increasing the amount of soil moisture also results in evaporative cooling (Supplementary Fig. 8a). However, this cooling is countered by a decrease in the regional surface albedo (Supplementary Fig. 6b) when the more reflective desert is replaced by darker vegetation. As a result the air temperature in the region increases (Fig. 3a) because of a sensible heat gain. Present-day AF simulations in boreal areas have produced similar albedo-related increases in temperature ${ }^{37}$. Another interesting, but not simulated, potential side effect of AF is that there would likely be less dust blown off of these desert regions if afforested (that is, both wind patterns and sources of dust may change). Since this dust contains iron and other nutrients that are known to fertilize the ocean ${ }^{38}$ and distant forests such as the Amazon, it is possible that productivity in these regions could decrease $\mathrm{s}^{39,40}$. Thus, an increase in productivity and carbon uptake in the afforested areas could result in a decrease in other areas, making this method potentially less effective as a carbon sink ${ }^{40}$.

Both OU and OIF increase local marine productivity (Table 3, Supplementary Fig. 6e,g), which may be beneficial for some species and fisheries ${ }^{27}$. However, the ecosystems of these fertilized regions (throughout the water column) would be disrupted by these changes 26,27 . Indeed, because of all the carbon that is locally sequestered and then respired during OIF, $\mathrm{pCO}_{2}$ increases and the $\mathrm{pH}$ decreases more rapidly near Antarctica than in the control run (Supplementary Fig. 13e,f). Other OIF studies ${ }^{26}$ have reported a similar result with regional declines in $\mathrm{pH}$ of up to 0.15 units (relative to a control run). A similar effect $\left(\mathrm{pCO}_{2}\right.$ increase, $\mathrm{pH}$ decrease) occurs during $\mathrm{OU}$ when sequestered carbon is upwelled, for example, in the tropical upwelling regions (Supplementary Fig. 13g,h). These methods also decrease productivity in some unfertilized regions because more nutrients are utilized before being transported out of the fertilized region ${ }^{25,26}$. Thus, non-local ecosystems and fisheries could also be affected.

As has previously been shown for $\mathrm{OIF}^{26}$, it and OU increase ocean deoxygenation (Fig. 2g; Supplementary Fig. 9c,d), due to the respiration (data not shown) of fertilization-induced organic matter in deeper waters. As a result the size of suboxic $\left(\mathrm{O}_{2}<10 \mu \mathrm{M}\right)$ regions changes (Supplementary Fig. 4), impacting marine ecosystems and biogeochemical cycles ${ }^{26,27}$. The simulated $265 \%$ increase in the size of the suboxic zones caused by OU may be particularly important because it could have climatic feedbacks due to the production of methane and $\mathrm{N}_{2} \mathrm{O}$, which are potent greenhouse gases, in low-oxygen waters ${ }^{27,41}$. Although the overall percent fraction that is suboxic with OIF decreases by $43 \%$ because of less productivity, export and respiration outside of the fertilized area ${ }^{26}$, oxygen declines in the Southern Ocean in our model (Supplementary Fig. 9c), with some regions becoming suboxic by the year 2125. This OIFinduced oxygen decline is much stronger than in an earlier OIF modelling study ${ }^{26}$ that found only minor decreases in oxygen $\left(60 \mathrm{mmol} \mathrm{m}^{-3}\right)$ in the Southern Ocean by the year 2110 . Since most of the oxygen is consumed in deeper waters that will not be at the surface, where air-sea gas exchange can occur, for tens to hundreds or thousands of years, discontinuing OIF and OU does not restore oxygen to the state that it is in the control simulation (Fig. 2h).

For OU there are also a number of simulated side effects related to the cooling of the Earth's surface. Terrestrial productivity is perturbed and in most places there is less soil respiration (Table 3, Supplementary Figs $6 \mathrm{~g}$ and $9 \mathrm{~h}$ ), which together results in more terrestrial C storage (Fig. 3h, Table 2). 
Table 4 | Side effects of the climate engineering methods.

\section{Method}

Afforestation

Ocean alkalinization

Ocean iron fertilization

Solar radiation

management

Ocean upwelling

\begin{abstract}
Alters terrestrial productivity and carbon storage

Increases regional precipitation

Increases local evaporative cooling
\end{abstract}

Increases marine productivity, except in some equatorial upwelling regions

Alters terrestrial productivity Alters ocean circulation, salinity, and stratification

Reduces soil temperatures

Reduces the rate of ocean acidification in the alkalized region

Increases marine productivity south of $40^{\circ} \mathrm{S}$

Reduces marine productivity north of $40^{\circ} \mathrm{S}$

Alters terrestrial productivity and respiration

Decreases surface-ocean $\mathrm{pCO}_{2}$ and the rate of ocean acidification

\section{Side effects}

Decreases the local surface albedo Increases adjacent regional surface air temperatures

Increases regional freshwater ocean input thereby reducing coastal salinity and altering currents and stratification

Cools surface atmosphere

Increases surface-ocean $\mathrm{pCO}_{2}$ and acidification in equatorial upwelling regions

Reduces precipitation

Enhances terrestrial carbon storage

Reduces the rate at which the saturation states of aragonite and calcite decrease

Increases surface-ocean $\mathrm{pCO}_{2}$ and acidification in some of the fertilized region

Alters precipitation patterns

Reduces total precipitation

Alters the carbon cycle
Reduces sea-ice melting

Increases ocean deoxygenation and the volume of oxygen minimum zones Imbalances the global heat budget Rapid climate change occurs when stopped

Increases ocean deoxygenation, but decreases the volume of tropical oxygen minimum zones

Reduces ocean deoxygenation Atmospheric $\mathrm{CO}_{2}$ continues to accumulate and rapid climate change occurs if the method is stopped
However, unlike in an earlier OU study ${ }^{27}$ where $80 \%$ of sequestered $\mathrm{C}$ was stored in the terrestrial system by the year 2100 , only $54 \%$ was in our study, which can be explained by the consideration of iron limitation and iron upwelling in our study (see Methods). Precipitation patterns are also altered (Supplementary Fig. 12g,h), with a decrease in total precipitation (Fig. 3e, Table 3) because of decreases in evaporation and evapotranspiration ${ }^{28}$. In addition, as in an earlier study ${ }^{27}$, OU decreases sea-ice loss and perturbs ocean temperature, salinity, stratification and circulation (Supplementary Figs 7g,h, 8g,h and 14b). Together, these side effects alter the planet's heat-budget and cause the Earth to take up additional heat and store it in the ocean's low-latitude subsurface waters (Supplementary Fig. 14b; see ref. 27 for further details). As a result this method cannot be stopped without causing rapid warming that ultimately exceeds that of the control run ${ }^{27}$ (Fig. 2d).

OA has few side effects that can be diagnosed with our model. The ones that we can diagnose reduce the rate of ocean acidification (Supplementary Fig. 13d) and keep the saturation states of aragonite and calcite higher than with most other methods (Table 3), despite higher oceanic carbon uptake (Fig. 3d, Table 2). However, other studies have noted that there are likely to be other side effects that impact marine ecosystems ${ }^{24,42}$ and shown that certain species physiology would be altered by $\mathrm{OA}^{43}$. Furthermore, this method is also likely to have a substantial impact on terrestrial systems due to the mining and production process associated with the alkalizing agent ${ }^{24,42}$.

For SRM there are a number of side effects related to the cooling of the Earth's surface. Terrestrial and marine productivity are perturbed and there is less soil respiration (Table 3, Supplementary Figs $6 i$ and $9 j$ ), which ultimately results in more terrestrial C storage (Table 2). For global terrestrial NPP, which is 1.7 $\mathrm{PgC}^{-1}$ higher in the year 2100 than in the control run, this increase is consistent with other SRM studies (for example, in the GeoMIP G1 experiments the model's mean change in NPP between the SRM runs and the quadrupled $\mathrm{CO}_{2}$ control runs was $\left.1.8 \mathrm{PgCy}^{-1}\right)^{44,45}$. Interestingly, this accumulation of $\mathrm{C}$ on land decreases surface-ocean $\mathrm{pCO}_{2}$ and reduces the rate of ocean acidification (Table 3, Supplementary Fig. 13i,j). Precipitation patterns are also altered, with a decrease in total precipitation (Fig. 3e; Table 3, Supplementary Fig. 12i,j), because of less evapotranspiration ${ }^{28}$ and evaporation ${ }^{22,46}$. Other studies ${ }^{22,28,44,47}$ have found a similar decrease in precipitation when SRM is implemented. However, since evapotranspiration in our model is more sensitive to $\mathrm{CO}_{2}$ increases than in other models and precipitation is simulated with a simple energy-moisture balance model, we performed the GeoMIP G1 experiment ${ }^{48}$ to gain a better understanding of how this particular result compares with other SRM experiments. This experiment (G1) involves instantaneously quadrupling the $\mathrm{CO}_{2}$ concentration (from preindustrial levels) while simultaneously reducing the solar constant to counteract this forcing (50-year simulation). In this experiment we found that global precipitation decreased by $0.26 \mathrm{~mm} \mathrm{~d}^{-1}$ (a 9\% reduction), which is more than the mean 0.1 (range: 0.1-0.2) $\mathrm{mm} \mathrm{d}^{-1}$ decrease (a mean reduction of $4.5 \%$ ) found with the GeoMIP models ${ }^{44}$. While this appears to be a substantial difference, when we spatially compare the results of last 10 years of our G1 simulation with the results from one of the GeoMIP models (MPI-ESM-LR), which has itself been comparatively assessed ${ }^{44}$, we are able to discern that the regional changes are higher in the MPI-ESM-LR even though the global mean effect is smaller (Supplementary Fig. 15). Thus, these GeoMIP model results actually indicate that larger, more extreme SRM-induced changes in regional tropical precipitation are possible, even if the global mean change is less than in our simulations. These differences likely reflect the differences in the atmospheric model components (for example, UVic's simple atmosphere versus the more complex, higher resolution one in the MPI-ESM-LR).

Another important side effect is that $\mathrm{CO}_{2}$ continues to accumulate and therefore SRM cannot be discontinued without causing rapid global change ${ }^{28-30}$ (Fig. 2, right panels). The $\mathrm{C}$ stored mostly in the soils during the deployment of SRM is released rapidly once temperatures increase. Finally, there are also 
likely to be other side effects beyond what we can diagnose, as other studies have indicated that if SRM is aerosol-based it will potentially affect atmospheric chemistry by depleting the ozone layer ${ }^{49}$ and altering the optical properties of the sky (that is, colour, whiteness) $)^{2}$. Furthermore, chemical-aerosol altering interactions may occur and reduce the method's effectiveness ${ }^{4}$. As discussed in other studies $3,5,28,46,49$, these side effects, especially in the case that SRM is discontinued, could severely disrupt ecosystems and human societies.

\section{Discussion}

While the effectiveness and the consequences of discontinuing the methods have, for some methods, been studied before $\mathrm{e}^{3,30}$ and evaluated and ranked in comparative frameworks ${ }^{3-5}$, this study for the first time uses an Earth system model for a comparative evaluation of the effectiveness of the different schemes. Unlike in previous studies, we thereby have been able to compare many of the side effects associated with the methods (Table 4) in a quantitative manner (Table 3). However, our study does have its limits. Foremost, our experiments were conducted with a single model for a limited number of idealized methods. Since every model has its own particular deficiencies and is only as good as its assumptions, further research with other models and scenarios is required. Model intercomparison projects such as GeoMIP ${ }^{48}$ and model uncertainty analyses, both individual and multi-model, will also be necessary to achieve a high level of confidence in the results. More methods may also need to be included in these evaluations, along with possible combinations of methods (for example, SRM and OA) and mitigation efforts (for example, SRM and carbon capture and storage). Another aspect that needs to be considered is that while we do discuss large-scale regional effects, these results are likely to be less robust than the global-scale ones due to the coarse resolution of our model. Therefore, future climate engineering studies should also be conducted with less heavily parameterized, higher resolution models to investigate regional effects. Furthermore, since these experiments were designed to evaluate what we deemed near-maximum effects, they did not consider any practical realities of deployment, which would have to be taken into account as the research becomes more focused.

Whether or not the magnitude (effectiveness) of the methods can be more than what we decided was optimistically feasible must be considered in future research. To further increase AF efficacy the forests could be better managed (that is, the careful husbandry of selected optimal species or even of genetically engineered species with the vegetation periodically harvested and the $\mathrm{C}$ biomass permanently removed from the active $\mathrm{C}$ cycle). More large-scale forests could also be planted, although this would likely bring AF into competition with existing areas of food production. For OIF, there is likely little that can be done to increase efficacy as a previous study ${ }^{25}$ found that fertilizing the areas outside of the Southern Ocean results in a negligible amount of carbon sequestration. For OU, the pipe location selection criteria (see ref. 27) could be modified to include iron and nitrate limitation or non-Redfield nutrient uptake. This would mostly result in the placement of pipes in the Southern Ocean, which is the major area where pipes currently aren't placed. Since nutrients are already plentiful here the increase in efficacy would be similar to that of OIF, but with the additional side effects of OU. For OA, the CDR efficacy could theoretically be increased if production and transport logistics, which we used to constrain this method, allow more of the alkalizing agent to be added to the ocean $^{50}$. However, any increase would take time since shipping and production capacity would need to be built up. Given the limited effectiveness of the CDR methods in our study, even with our optimistically large deployments, a very substantial increase in the magnitude (efficacy) mentioned above would be needed to make much of a difference. However, for SRM, insolation could have been reduced more rapidly with our idealized methodology than in Fig. 4a (that is, as in other SRM experiments when it is deployed later in the twenty first century to counter higher temperatures ${ }^{28,51}$ ), although there would be no reason to do so unless temperatures below pre-industrial levels were desired. Moreover, from a practical standpoint there are some legitimate concerns that have been discussed in other studies ${ }^{3,49}$ about the practical logistics of aerosol deployment or other SRM methods.

In summary, our study suggests that even if continuously deployed on a massive scale, the evaluated CDR-based methods are able to only sequester an amount of atmospheric $\mathrm{CO}_{2}$ that is small compared with cumulative anthropogenic emissions in the RCP 8.5 scenario and are thus unable to prevent the mean surface temperature from increasing to well above $2{ }^{\circ} \mathrm{C}$ by the year 2100 (Figs 2a,c and 3; Table 2). This is a result that holds true even if the methods that can be safely stopped (AF, OIF and OA) are combined (Table 2; Supplementary Fig. 16). SRM is the method that has the largest potential for preventing warming and even for sequestering carbon, which is an effectiveness-amplifying side effect. However, SRM also has some of the largest side effects and cannot be discontinued without causing rapid climate change (Fig. 2; Supplementary Figs 6i, 10 and 12). Together, these results suggest that if $\mathrm{CO}_{2}$ emissions remain high, the climate engineering methods discussed here should not be solely counted on to prevent warming or large-scale changes to the Earth system. Indeed, given the limited effectiveness of most of the evaluated methods, our results suggest, in agreement with other studies ${ }^{3}$, that $\mathrm{CO}_{2}$ emission mitigation seems the most effective way to prevent climate change. Climate engineering does not appear to be an alternative option, although it could possibly be used to compliment mitigation ${ }^{3}$. However, if climate engineering is seriously considered as one of the means of preventing climate change, care must be taken when evaluating whether the potential reductions in atmospheric carbon and temperature of a particular method are worth the risks and costs of its side effects.

\section{Methods}

Model description. The model (UVic version 2.9) consists of three dynamically coupled components: a three-dimensional (3D) general circulation model of the ocean that includes a dynamic-thermodynamic sea-ice model, a terrestrial model and a simple one-layer atmospheric energy-moisture balance model. All components have a common horizontal resolution of $3.6^{\circ}$ longitude $\times 1.8^{\circ}$ latitude. The oceanic component, which is in the configuration described in ref. 8 , has 19 levels in the vertical with thicknesses ranging from $50 \mathrm{~m}$ near the surface to $500 \mathrm{~m}$ in the deep ocean. The terrestrial model of vegetation and carbon cycles ${ }^{52}$ is based on the Hadley Center model TRIFFID. The atmospheric energy-moisture balance model interactively calculates heat and water fluxes to the ocean, land and sea ice. Wind velocities, which are used to calculate the momentum transfer to the ocean and sea-ice model, surface heat and water fluxes, and the advection of water vapour in the atmosphere, are determined by adding wind and wind stress anomalies (as determined from surface pressure anomalies that are calculated from deviations in pre-industrial surface air temperature) to prescribed NCAR/NCEP monthly climatological wind data ${ }^{53}$. The model has been extensively used in climate change studies and is also well validated under pre-industrial to present-day conditions ${ }^{7-10,54}$.

Experimental design. The model was spun up for 10,000 years under pre-industrial atmospheric and astronomical boundary conditions and then run from 1765 to 2000 using historical fossil fuel and land-use carbon emissions. From the year 2000 to 2100 the model was forced with $\mathrm{CO}_{2}$ emissions following the Representative Concentration Pathway (RCP) 8.5 scenario, which is a 'business-as-usual' high $\mathrm{CO}_{2}$ emission scenario ${ }^{6}$. Continental ice sheets, volcanic forcing and astronomical boundary conditions were held constant to facilitate the experimental set-up and analyses (that is, prevent confounding feedback effects). Supplementary Figs 1-3 show the 'control' run results. Simulated climate engineering (Table 1) starts in year 2020 and is either applied continuously until the year 2100 or stopped after 1,10 and 50 years, with the runs continuing 
thereafter until year 2100 (Fig. 1). All methods, except for SRM and OU, are instantaneously deployed and stopped at full scale.

Simulated AF. The simulated AF of North Africa (the Sahara desert) and the Australian Outback is based on a previous study ${ }^{39}$, which we have chosen to replicate because this avoids conflicts with current food production, even though it requires expensive large-scale irrigation measures. Irrigation is simulated by forcing the soil moisture to have a constant value of $360 \mathrm{~kg} \mathrm{~m}^{-2}$ (Supplementary Fig. 17), which then allows vegetation to grow and remove $\mathrm{CO}_{2}$ from the atmosphere. The irrigated regions were chosen to replicate the previous experiment ${ }^{39}$ and we refer readers to this article for justification of the chosen locations. In our simulations only the direct effects of AF on carbon uptake, surface albedo and the energymoisture balance are considered. The frictional effect on winds is not investigated, nor is the potential limitation of vegetative growth by nutrients other than carbon. The possible reduction of desert dust transport and deposition are not considered here either and will be further investigated elsewhere.

Simulated OU. Simulated OU was based on a previous study with the UVic model $^{27}$. This method places 'pipes' that pump water from the specified lower end of the pipe (up to $1,000 \mathrm{~m}$ deep) to the ocean surface, in areas where upwelling has been calculated to reduce surface-ocean $\mathrm{pCO}_{2}$ (Supplementary Fig. 14a). The simulated upwelling works by transferring water adiabatically from the grid box at the lower end of the pipe to the surface grid box at a rate of $1 \mathrm{~cm} \mathrm{~d}^{-1}$. A compensating downwelling velocity at all intermediate levels insures volume conservation. The modelled pipes operate at any water column at any time for which a pipe-induced local reduction in surface $\mathrm{pCO}_{2}$ can be expected (included in this calculation is the assumption that surface phosphate concentrations are $<0.4 \mathrm{mmol} \mathrm{m}^{-3}$ so that a fertilization effect occurs). In contrast to the previous study ${ }^{27}$, the ecosystem model now includes phytoplankton iron limitation ${ }^{8}$ and the method was modified so that iron is not limiting in the grid cells where the pipes are located. This implementation relies on the assumption that either there is bioavailable iron at the depths from which the pipes draw water or that particlebound iron is desorbed and becomes bioavailable when it is pumped to the surface. Observations ${ }^{55}$ indicate that in ocean regions where dust deposition is low, dissolved iron concentrations are higher at depth than at the surface, suggesting that artificially upwelling these waters will increase surface iron concentrations. Since bioavailable iron is quickly utilized or abiotically scavenged ${ }^{38,55}$ it was also assumed that upwelled dissolved iron is removed before it can be exported to adjacent grid cells.

Simulated OA. OA by $\mathrm{Ca}(\mathrm{OH})_{2}$ addition was simulated by evenly increasing the total alkalinity of surface waters between $70^{\circ} \mathrm{N}$ and $60^{\circ} \mathrm{S}$ (that is, in ice-free waters accessible throughout the year) (Supplementary Fig. 18). The premise behind this method is that the addition and dissolution of $\mathrm{Ca}(\mathrm{OH})_{2}$ in seawater increases the total alkalinity and thereby removes $\mathrm{CO}_{2}$ from seawater in the following reaction:

$$
\mathrm{Ca}(\mathrm{OH})_{2}+2 \mathrm{CO}_{2} \rightarrow \mathrm{Ca}^{2+}+2 \mathrm{HCO}_{3}^{-}
$$

As a result of (1) the ocean takes up more $\mathrm{CO}_{2}$ due to the conversion of $\mathrm{CO}_{2}$ to $\mathrm{HCO}_{3}^{-}$at a molar ratio of 2 moles per added mole of $\mathrm{Ca}(\mathrm{OH})_{2}$. Equation (1) also implies that for every mole of $\mathrm{Ca}(\mathrm{OH})_{2}$ added total alkalinity increases by 2 moles. Since limestone, from which $\mathrm{Ca}(\mathrm{OH})_{2}$ is derived, is readily abundant the major limits are either those of production or the capacity to deliver it. The amount we added, $10 \mathrm{Pg}^{-1}$, is based on another study ${ }^{24}$, which estimated that the total transport capacity of all large cargo ships and tankers is $\sim 10 \mathrm{Pg}^{-1}$. Our simulation of OA may thus be viewed as of maximum intensity based on current transport capacity.

Simulated OIF. To simulate the maximum potential of OIF we followed previous studies ${ }^{26,56}$ and focused on the Southern Ocean as the region with the largest carbon sequestration potential by OIF because it has the largest inventory of unused surface macronutrients, has been identified as being iron limited ${ }^{57,58}$ and is a site of large water-mass transformations ${ }^{59,60}$, which help to keep regionally exported carbon in the ocean's interior. Furthermore, Southern Ocean surface $\mathrm{pCO}_{2}$ drawdown and deep carbon export has been observed during iron fertilization experiments ${ }^{61,62}$ and simulated by modelling studies ${ }^{25,26}$. Our simulated Southern OIF works in an idealized manner by simply releasing phytoplankton from iron limitation everywhere south of $40^{\circ}$.

Simulated SRM. There is, so far, little information about the maximum possible intensity of SRM. In this study we set the intensity of SRM such that SRM restores and maintains near pre-industrial atmospheric temperatures. The methodology is based on previous SRM simulations with the UVic model ${ }^{28}$ and works by reducing the radiative forcing in the model (Fig. 4a) to mimic what would happen if hypothetical SRM techniques, such as the stratospheric injection of reflective aerosols or space-based sunshades ${ }^{3}$, were successfully deployed. As in a previous study ${ }^{28}$ SRM is represented by applying a factor, $K_{\mathrm{g}}$, during each time step to incoming solar radiation (the solar constant), $S_{\mathrm{C}}^{o}$, before the incoming shortwave radiation at the top of the atmosphere; $S_{\mathrm{C}}$, is calculated for each grid cell so that

$$
S_{\mathrm{C}}=S_{\mathrm{C}}^{o} \cdot\left(1-K_{\mathrm{g}}\right)
$$

and

$$
K_{\mathrm{g}}=\left(\frac{F \cdot \ln \left(\frac{\mathrm{CO}_{2}}{\chi_{\mathrm{CO}_{2}}}\right)}{\frac{S_{\mathrm{C}}^{\circ}}{4} \cdot \alpha_{\mathrm{P}}}\right)
$$

In (3) $\mathrm{F}$ is the atmospheric $\mathrm{CO}_{2}$ radiative forcing term ${ }^{53}$ and has a constant value of $5.35 \mathrm{~W} \mathrm{~m}{ }^{-2}, \mathrm{CO}_{2}$ is the simulated atmospheric $\mathrm{CO}_{2}$ concentration, and $\chi_{\mathrm{CO}_{2}}$, which equals 280 p.p.m., is the atmospheric $\mathrm{CO}_{2}$ concentration that corresponds to the target radiative forcing, and $\alpha_{\mathrm{P}}$ equals 0.7 , which is approximately one minus the globally averaged planetary albedo.

\section{References}

1. Peters, G. P. et al. The challenge to keep global warming below $2^{\circ} \mathrm{C}$. Nat. Clim. Chang. 3, 4-6 (2013).

2. Crutzen, P. Albedo enhancement by stratospheric sulfur injections: a contribution to resolve a policy dilemma? Clim. Change 77, 211-220 (2006).

3. Vaughan, N. E. \& Lenton, T. M. A review of climate geoengineering proposals. Clim. Change 109, 745-790 (2011).

4. Boyd, P. W. Ranking geo-engineering schemes. Nat. Geosci. 1, 722-724 (2008).

5. Lenton, T. M. \& Vaughan, N. E. The radiative forcing potential of different climate geoengineering options. Atmos. Chem. Phys. 9, 5539-5561 (2009).

6. Meinshausen, M. et al. The RCP greenhouse gas concentrations and their extensions from 1765 to 2300. Clim. Change 109, 213-241 (2011).

7. Eby, M. et al. Lifetime of anthropogenic climate change: millennial time scales of potential CO2 and surface temperature perturbations. J. Clim. 22, 2501-2511 (2009).

8. Keller, D. P., Oschlies, A. \& Eby, M. A new marine ecosystem model for the University of Victoria Earth System Climate Model. Geosci. Model Dev. 5, 1195-1220 2012 (2012).

9. Eby, M. et al. Historical and idealized climate model experiments: an intercomparison of Earth system models of intermediate complexity. Clim. Past 9, 1111-1140 (2013).

10. Zickfeld, K. et al. Long-term climate change commitment and reversibility: an EMIC Intercomparison. J. Clim. 26, 5782-5809 (2013).

11. Weaver, A. J. et al. Stability of the Atlantic meridional overturning circulation: a model intercomparison. Geophys. Res. Lett. 39, L20709 (2012).

12. Knutti, R. \& Sedlacek, J. Robustness and uncertainties in the new CMIP5 climate model projections. Nat. Clim. Chang. 3, 369-373 (2013).

13. Moore, J. K., Lindsay, K., Doney, S., Long, M. C. \& Misumi, K. Marine ecosystem dynamics and biogeochemical cycling in the Community Earth System Model (CESM1 (BGC)): comparison of the 1990s with the 2090s under the RCP 4.5 and RCP 8.5 Scenarios. J. Clim. 26, 9291-9312 (2013).

14. Oschlies, A., Schulz, K. G., Riebesell, U. \& Schmittner, A. Simulated 21st century's increase in oceanic suboxia by $\mathrm{CO}_{2}$-enhanced biotic carbon export. Global Biogeochem. Cycles 22, doi:10.1029/2007GB003147 (2008).

15. Duteil, O. \& Oschlies, A. Sensitivity of simulated extent and future evolution of marine suboxia to mixing intensity. Geophys. Res. Lett. 38, L06607 (2011).

16. Stramma, L., Johnson, G. C., Sprintall, J. \& Mohrholz, V. Expanding oxygen minimum zones in the tropical oceans. Science 230, 655-658 (2008).

17. Ahlström, A., Schurgers, G., Arneth, A. \& Smith, B. Robustness and uncertainty in terrestrial ecosystem carbon response to CMIP5 climate change projections. Environ. Res. Lett. 7, 044008 (2012).

18. Dirmeyer, P. A., Jin, Y., Singh, B. \& Yan, X. Trends in land-atmosphere interactions from CMIP5 simulations. J. Hydrometeorol. 14, 829-849 (2013).

19. Liu, C. \& Allan, R. P. Observed and simulated precipitation responses in wet and dry regions 1850-2100. Environ. Res. Lett. 8, 034002 (2013).

20. Allan, R. et al. Physically consistent responses of the global atmospheric hydrological cycle in models and observations. Surveys Geophys. 1-20 (2013).

21. Wentz, F. J., Ricciardulli, L., Hilburn, K. \& Mears, C. How much more rain will global warming bring? Science 317, 233-235 (2007)

22. Fyfe, J. C., Cole, J. N. S., Arora, V. K. \& Scinocca, J. F. Biogeochemical carbon coupling influences global precipitation in geoengineering experiments. Geophys. Res. Lett. 40, 651-655 (2013).

23. Keenan, T. F. et al. Increase in forest water-use efficiency as atmospheric carbon dioxide concentrations rise. Nature 499, 324-327 (2013).

24. Köhler, P., Abrams, J. F., Völker, C., Hauck, J. \& Wolf-Gladrow, D. A. Geoengineering impact of open ocean dissolution of olivine on atmospheric $\mathrm{CO}_{2}$, surface ocean pH and marine biology. Environ. Res. Lett. 8, 014009 (2013).

25. Aumont, O. \& Bopp, L. Globalizing results from ocean in situ iron fertilization studies. Global Biogeochem. Cycles 20, GB2017 (2006).

26. Oschlies, A., Koeve, W., Rickels, W. \& Rehdanz, K. Side effects and accounting aspects of hypothetical large-scale Southern Ocean iron fertilization. Biogeosciences 7, 4017-4035 (2010). 
27. Oschlies, A., Pahlow, M., Yool, A. \& Matear, R. J. Climate engineering by artificial ocean upwelling-channelling the sorcerer's apprentice. Geophys. Res. Lett. 37, L04701 (2010).

28. Matthews, H. D. \& Caldeira, K. Transient climate-carbon simulations of planetary geoengineering. Proc. Natl Acad. Sci. USA 104, 9949-9954 (2007).

29. Brovkin, V. et al. Geoengineering climate by stratospheric sulfur injections: Earth system vulnerability to technological failure. Clim. Change 92, 243-259 (2009).

30. Jones, A. et al. The impact of abrupt suspension of solar radiation management (termination effect) in experiment G2 of the Geoengineering Model Intercomparison Project (GeoMIP). J. Geophys. Res. Atmos. 118, 9743-9752 (2013).

31. Llanillo, P., Jones, P. D. \& von Glasow, R. The Influence of stratospheric sulphate aerosol deployment on the surface air temperature and the risk of an abrupt global warming. Atmosphere 1, 62-84 (2010).

32. Ross, A. \& Matthews, H. D. Climate engineering and the risk of rapid climate change. Environ. Res. Lett. 4, 045103 (2009).

33. Bala, G. et al. Combined climate and carbon-cycle effects of large-scale deforestation. Proc. Natl Acad. Sci. USA 104, 6550-6555 (2007).

34. Dekker, S. C. et al. Biogeophysical feedbacks trigger shifts in the modelled vegetation-atmosphere system at multiple scales. Biogeosciences 7, 1237-1245 (2010).

35. Egleston, E. S., Sabine, C. \& Morel, F. M. M. Revelle revisited: Buffer factors that quantify the response of ocean chemistry to changes in DIC and alkalinity. Global Biogeochem. Cycles 24, GB1002 (2010).

36. Betts, R. A. et al. Projected increase in continental runoff due to plant responses to increasing carbon dioxide. Nature 448, 1037-1041 (2007).

37. Betts, R. A. Offset of the potential carbon sink from boreal forestation by decreases in surface albedo. Nature 409, 187-190 (2000).

38. Galbraith, E. D., Gnanadesikan, A., Dunne, J. P. \& Hiscock, M. R. Regional impacts of iron-light colimitation in a global biogeochemical model. Biogeosciences 7, 1043-1064 (2010).

39. Ornstein, L., Aleinov, I. \& Rind, D. Irrigated afforestation of the Sahara and Australian Outback to end global warming. Clim. Change 97, 409-437 (2009).

40. Ridgwell, A., Maslin, M. A. \& Watson, A. J. Reduced effectiveness of terrestrial carbon sequestration due to an antagonistic response of ocean productivity. Geophys. Res. Lett. 29, 19-1-19-4 (2002).

41. Zamora, L. M. et al. Nitrous oxide dynamics in low oxygen regions of the Pacific: insights from the MEMENTO database. Biogeosciences 9, 5007-5022 (2012).

42. Harvey, L. D. D. Mitigating the atmospheric CO2 increase and ocean acidification by adding limestone powder to upwelling regions. J. Geophys. Res. Oceans 113, C04028 (2008)

43. Cripps, G., Widdicombe, S., Spicer, J. I. \& Findlay, H. S. Biological impacts of enhanced alkalinity in Carcinus maenas. Mar. Pollut. Bull. 71, 190-198 (2013).

44. Kravitz, B. et al. Climate model response from the Geoengineering Model Intercomparison Project (GeoMIP). J. Geophys. Res. Atmos. 118, 8320-8332 (2013).

45. Naik, V., Wuebbles, D. J., Delucia, E. H. \& Foley, J. A. Influence of geoengineered climate on the terrestrial biosphere. Environ. Manage. 32, 373-381 (2003)

46. Feichter, J. \& Leisner, T. Climate engineering: a critical review of approaches to modify the global energy balance. Eur. Phys. J. Spec. Top. 176, 81-92 (2009).

47. Bala, G., Duffy, P. B. \& Taylor, K. E. Impact of geoengineering schemes on the global hydrological cycle. Proc. Natl Acad. Sci. USA 105, 7664-7669 (2008).

48. Kravitz, B. et al. The Geoengineering Model Intercomparison Project (GeoMIP). Atmos. Sci. Lett. 12, 162-167 (2011).
49. Heckendorn, P. et al. The impact of geoengineering aerosols on stratospheric temperature and ozone. Environ. Res. Lett. 4, 045108 (2009).

50. Kheshgi, H. S. Sequestering atmospheric carbon dioxide by increasing ocean alkalinity. Energy 20, 915-922 (1995).

51. Schmidt, H. et al. Solar irradiance reduction to counteract radiative forcing from a quadrupling of $\mathrm{CO} 2$ : climate responses simulated by four earth system models. Earth Syst. Dynam. 3, 63-78 (2012).

52. Meissner, K. J., Weaver, A. J., Matthews, H. D. \& Cox, P. M. The role of land surface dynamics in glacial inception: a study with the UVic Earth System Model. Clim. Dynam. 21, 515-537 (2003).

53. Weaver, A. J. et al. The UVic earth system climate model: model description, climatology, and applications to past, present and future climates. Atmos. Ocean 39, 361-248 (2001).

54. Zickfeld, K., Eby, M., Matthews, H. D., Schmittner, A. \& Weaver, A. J. Nonlinearity of Carbon Cycle Feedbacks. J. Clim. 24, 4255-4275 (2011).

55. Moore, J. K. \& Braucher, O. Sedimentary and mineral dust sources of dissolved iron to the world ocean. Biogeosciences 5, 631-656 (2008).

56. Sarmiento, J., Slater, R. D., Dunne, J., Gnanadesikan, A. \& Hiscock, M. R. Efficiency of small scale carbon mitigation by patch iron fertilization. Biogeoscience 7, 3593-3624 (2010).

57. Boyd, P. W., Arrigo, K. R., Strzepek, R. \& van Dijken, G. L. Mapping phytoplankton iron utilization: insights into Southern Ocean supply mechanisms. J. Geophys. Res. 117, C06009 (2012).

58. Martin, J. H. in Primary Productivity and Biogeochemical Cycles in the Sea (eds Falkowski, P. G. \& Woodhead, A. D.) 123-137 (Plenum Press, 1992).

59. Iudicone, D. et al. Water masses as a unifying framework for understanding the Southern Ocean carbon cycle. Biogeosciences 8, 1031-1052 (2011).

60. Iudicone, D., Speich, S., Madec, G. \& Blanke, B. The global conveyor belt from a Southern Ocean perspective. J. Phys. Oceanogr. 38, 1401-1425 (2008).

61. Smetacek, V. et al. Deep carbon export from a Southern Ocean iron-fertilized diatom bloom. Nature 487, 313-319 (2012).

62. Boyd, P. W. et al. Mesoscale iron enrichment experiments 1993-2005: synthesis and future directions. Science 315, 612-617 (2007).

\section{Acknowledgements}

We thank Fabian Reith, Soumya Paul and Jayjit Dutta for analysing some of the model output. This work is a contribution to the German DFG-funded Priority Program 'Climate Engineering: Risks, Challenges, Opportunities?' (SPP 1689).

\section{Author contributions}

A.O. conceived this study. All authors designed the experiments. D.P.K. conducted the model runs and performed the analysis. The manuscript was written by D.P.K. with intellectual contributions and editing input from A.O. and E.Y.F.

\section{Additional information}

Supplementary Information accompanies this paper at http://www.nature.com/ naturecommunications

Competing financial interests: The authors declare no competing financial interests

Reprints and permission information is available online at http://npg.nature.com/ reprintsandpermissions/

How to cite this article: Keller, D. P. et al. Potential climate engineering effectiveness and side effects during a high $\mathrm{CO}_{2}$-emission scenario. Nat. Commun. 5:3304 doi: $10.1038 /$ ncomms4304 (2014)

cc)(1) (2) This work is licensed under a Creative Commons AttributionNonCommercial-ShareAlike 3.0 Unported License. To view a copy of this license, visit http://creativecommons.org/licenses/by-nc-sa/3.0/ 